\title{
Efeitos da secularização do Estado, do pluralismo e do mercado religiosos sobre as igrejas pentecostais
}

Ricardo Mariano ${ }^{1}$

Este artigo discute, primeiramente, a perspectiva teórica de alguns sociólogos norte-americanos acerca dos efeitos da separação Igreja-Estado sobre o campo religioso. Em seguida, com base em pesquisa empírica, mostra alguns efeitos da secularização do Estado brasileiro e da consolidação do pluralismo e do mercado religiosos sobre o pentecostalismo. Revela que, entre tais efeitos, destacam-se a adoção de modelos de gestão de cunho empresarial, a centralização da gestão administrativa e financeira, a concentração do poder eclesiástico, a profissionalização dos quadros ministeriais, o uso de estratégias de marketing e de métodos heterodoxos de arrecadação, a fixação de metas de produtividade para pastores e bispos, a minimização e o

\footnotetext{
${ }^{1}$ Ricardo Mariano é doutor em sociologia pela USP, autor do livro Neopentecostais: sociologia do novo pentecostalismo no Brasil (Loyola, 1999) e professor de sociologia do Programa de Pós-Graduação em Ciências Sociais da PUCRS. Endereço: rmariano1 @uol.com.br
} 
abandono de práticas ascéticas e sectárias, a adaptação dos serviços mágicoreligiosos aos interesses materiais e ideais dos fiéis e virtuais adeptos.

A secularização do aparato jurídico-político constitui processo histórico decisivo na formação das sociedades modernas ocidentais. A separação Estado-Igreja, que no Brasil ocorre concomitantemente com o advento do regime republicano, não só faz parte desse processo de secularização ${ }^{2}$ como o impulsiona. Com a separação, o Estado, além de adquirir autonomia em relação ao grupo religioso ao qual se aliava, amplia sua dominação jurídica e política sobre a esfera religiosa. A secularização do aparato jurídicopolítico, além de reiterar a autonomia e a supremacia do direito em relação às outras formas de ordens normativas, de reduzir praticamente a pó as pretensões dos grupos religiosos em impor suas normas ao conjunto da sociedade, de submetê-las ao império da lei, relativiza, relega a segundo plano e desqualifica as demais fontes de normatividade.

A separação Estado-Igreja e a moderna secularização do Estado propiciaram a efetivação de profundas mudanças no campo religioso. Instaurada pelos Estados liberais - cujo ideário político preconiza a neutralidade religiosa do Estado e a restrição da religião à vida privada ou à particularidade das consciências individuais -, a separação desmantelou o monopólio religioso, erodindo ao menos parcialmente as prerrogativas que a religião oficial usufruía de sua aliança política com o Estado, e resultou na garantia legal de liberdade religiosa, na defesa da tolerância religiosa e na proteção do pluralismo religioso. Com sua secularização, o Estado, portanto, passou a garantir legalmente a liberdade dos indivíduos para escolherem voluntariamente que fé professar e o livre exercício dos grupos religiosos.

No caso brasileiro, a ampla liberdade religiosa resultante da secularização do Estado está na raiz da desmonopolização religiosa, da formação e expansão do pluralismo religioso e, por conseqüência, do acirramento da concorrência religiosa. Isto é, a concessão de liberdade religiosa e a separação Igreja-Estado romperam definitivamente o monopólio católico, abrindo caminho para que outros grupos religiosos pudessem ingressar e se formar no país, disputar e conquistar novos espaços na sociedade, adquirir legitimidade social e consolidar sua presença institucional. Fenômeno que não ocorreu do dia para a noite, mas paulatinamente e aos tropeços. A perseguição policial aos cultos afro-brasileiros efetuada até os anos 50 atesta a longa via-

\footnotetext{
${ }^{2}$ Flávio Pierucci (1998) mostra que o conceito weberiano de secularização envolve, acima de tudo, o longo processo de racionalização ocidental da ordem jurídico-política, o disestablishment ou a separação da religião do Estado, que, na modernidade, se torna laico, domínio da lei e guardião do direito formal. Direito que, nesse contexto, por ser dessacralizado, se torna legitimamente revisável.
} 
crúcis percorrida pela liberdade religiosa no país. De todo modo, atualmente o Estado brasileiro trata de modo isonômico, pelo menos no plano jurídico, os diferentes grupos religiosos. Na França, em contraste, vigora clara discriminação legal - baseada em critérios políticos, jurídicos, fiscais, culturais, históricos - contra os grupos classificados como seitas pelo Estado. Exemplo que demonstra que a separação Estado-Igreja e a secularização do Estado não conduzem necessariamente aos mesmos resultados nos diferentes países. Com efeito, há maior liberdade religiosa no Brasil do que na França. Que o digam as "seitas" do país de Voltaire.

A discussão sobre a separação Estado-Igreja e sua influência sobre o campo religioso encontram-se nas obras ${ }^{3}$ de Stark, Bainbridge, Iannaccone e Finke, pesquisadores cujos trabalhos vêm polarizando o debate ${ }^{4}$ acadêmico na sociologia da religião norte-americana ${ }^{5}$ desde o início da década de 1990. Eles defendem a tese de que a separação Estado-Igreja nos Estados Unidos e noutros países favorecera a expansão do pluralismo religioso e, com isso, resultara numa maior mobilização religiosa dos agentes religiosos e da população. A separação teria contribuído para a diversificação institucional do campo religioso ao pôr fim ao monopólio religioso, às perseguições religiosas e aos privilégios legais da religião dominante e, ao mesmo tempo, ao conceder e assegurar ampla liberdade religiosa aos indivíduos e aos demais agentes e grupos religiosos. Em suma, da separação resultam a desmonopolização religiosa, a liberdade e o pluralismo religiosos. Da liberdade e do pluralismo religiosos derivam o recrudescimento da concorrência religiosa, a dilatação do ativismo militante dos agentes religiosos, o crescimento da oferta de novos produtos e serviços religiosos e, como efeito disso, a maior mobilização religiosa da população. Incremento de participação religiosa que, para esses pesquisadores, põe em xeque a tese da secularização. Da

\footnotetext{
${ }^{3}$ Entre dezenas de trabalhos, Stark e Bainbridge são autores de dois importantes livros: The future of religion e A theory of religion. Roger Finke e Rodney Stark publicaram The churching of America - 1776-1990: Winners and losers in our religious economy. Em 1997, Lawrence A. Young organizou o livro Rational choice theory and religion: Summary and assessment, contendo as principais perspectivas teóricas desses pesquisadores, além de artigos que as criticam. No paper "Work in progress toward a new paradigm for the sociological study of religion in the United States", R. Stephen Warner (1993) elabora balanço da teoria sociológica desses pesquisadores, entre os quais se inclui o economista Laurence Iannaccone (1994; 1995; 1997), autor de diversos artigos na área, alguns deles em conjunto com Stark (Iannaccone e Stark, 1992; 1993). Ver também o importante trabalho de Finke (1997).

${ }^{4}$ Sobre esse debate, ver Collins (1993; 1997), Warner (1993b), Chaves (1995), Ellison (1995), Sherkat (1997), Hadaway, Marler, Chaves (1998), Shea (2001).

${ }_{5}$ Alguns pesquisadores latino-americanos têm se baseado na teoria desses estudiosos norteamericanos. Alejandro Frigerio (1998a, 1998b), Floreal Forni (2000), Flávio Pierucci (1999b) e Ricardo Mariano (2001) adotam algumas concepções teóricas contidas nessa perspectiva teórica.
} 
secularização da vida privada, talvez, mas de modo algum da secularização do Estado, cumpre frisar.

A esse respeito cabe ponderar que a expansão acelerada de vários grupos religiosos, mesmo que majoritariamente mágicos, em nada vem alterando as conquistas secularizantes da modernidade ocidental, como a dessacralização e racionalização da ordem jurídico-política ou a laicização do Estado. Tal expansão religiosa, a meu ver, não tem condição de reverter a profunda secularização ocorrida no Ocidente, processo que está jurídica, política e socialmente por demais enraizado nas entranhas de nossas principais instituições governamentais, econômicas, culturais e sociais. De modo que, a despeito do extenso crescimento religioso em nosso país a partir da segunda metade do século XX, os elementos institucionais e hegemônicos constitutivos do Brasil na atualidade, são, como assevera Reginaldo Prandi (1991, p. 65), "tipicamente capitalistas, racionais, burocratizados, dessacralizados". Pois "essa sociedade é", continua, "moderna, e como moderna é profana: sua civilização é desencantada, não depende do sobrenatural. Suas instituições, seus governos, mercados, escolas, meios de comunicações, tudo é não-religioso" (Ibid., p. 65).

Nas décadas de 70 e 80, antes da publicação das idéias de Stark e Bainbridge, os trabalhos de Peter Berger - Um modelo de mercado para a análise da ecumenicidade (1963) e, em especial, $O$ dossel sagrado (publicado originalmente em 1969) - constituíam, segundo Stephen Warner (1993a), verdadeiro paradigma na sociologia da religião norte-americana. Amplamente conhecida dentro e fora dos Estados Unidos, a perspectiva de Berger sustenta que o pluralismo religioso apresenta efeito secularizador por multiplicar o número de estruturas de plausibilidade, relativizar o conteúdo dos discursos religiosos concorrentes, torná-los assunto privado, subjetivá-los e, em razão disso, gerar ceticismo e descrença.

Em radical oposição ao que preconizava Berger, que interpreta o pluralismo religioso como evidência de fraqueza da religião na modernidade, Stark e Iannaccone (1992, p. 2031-2032) defendem categoricamente a tese de que "a participação religiosa é mais alta onde um número proporcionalmente maior de empresas religiosas competem". Os níveis de compromisso e participação religiosos da população, asseguram, são mais baixos nos campos religiosos dominados por monopólios e, inversamente, mais altos onde vigora o pluralismo religioso. A explicação que oferecem para sustentar essa tese, alvo de intenso debate, é relativamente simples. Com a secularização do Estado, o fim do monopólio e a garantia estatal da liberdade e tolerância religiosas, ocorrem o aumento do número de agentes e grupos religiosos e a diversificação da oferta de produtos e serviços religiosos. Nesse contexto pluralista, as agremiações religiosas, para sobreviver e cres- 
cer, são compelidas a concorrer, disputar mercado. Para tanto, muitas organizações religiosas, além de reforçar seu proselitismo, estimulando o ativismo do clero e a militância dos leigos, procuram, como forma de atrair clientela e recrutar novos adeptos, conquistar novos nichos de mercado, especializando-se na oferta de produtos e serviços adaptados aos interesses e preferências específicos de determinados estratos sociais. De modo que o contexto pluralista, por conta de seu estímulo à competição e à diversificação da oferta de produtos e serviços religiosos, aumenta a probabilidade de que os interesses materiais e ideais dos mais distintos grupos sociais sejam contemplados e atendidos. Numa situação de monopólio, em contraste, a diversidade de produtos e serviços religiosos tende a ser mais limitada, na medida em que uma única religião tem menor capacidade de diversificar sua oferta de bens de salvação - sem comprometer sua mensagem e seus propósitos - para atender, satisfatória e concomitantemente, à heterogeneidade dos interesses e preferências religiosos dos mais distintos grupos sociais de uma sociedade complexa e pluralista.

No caso brasileiro, a situação pluralista e concorrencial consolidou-se tão-somente na segunda metade do século $\mathrm{XX}$, mais de meio século depois da separação Igreja-Estado. Desde então a lógica de mercado passou a orientar as ações organizacionais, religiosas e proselitistas de vários grupos religiosos, sobretudo de certas denominações pentecostais. O que não significa que essa lógica predomine atualmente sobre o conjunto das igrejas pentecostais. Não se trata disso. A despeito do fato de que as pressões do mercado religioso vêm exercendo crescente influência nos rumos do pentecostalismo, observa-se que diversas igrejas desse movimento religioso muito diversificado internamente nos planos institucional, organizacional e teológico, na composição social de seus membros e na sua relação com a cultura e a sociedade abrangente - se baseiam em princípios, tradições, doutrinas e práticas dissociados, em boa medida, dos imperativos do mercado religioso.

Apesar disso, várias igrejas pentecostais, no afã de superar a concorrência religiosa e de atingir metas evangelísticas as mais ambiciosas, vêm perseguindo essa lógica. Algo que pode ser observado já na adoção que, nas últimas décadas, elas vêm fazendo de um modelo de organização e gestão denominacional de molde empresarial, cujo efeito é acentuar ainda mais a concentração e verticalização do poder eclesiástico e a centralização administrativa e financeira. Organização e gestão pouco compatíveis com governos eclesiásticos congregacionais, que, além de descentralizados e, em teoria, democráticos, costumam facultar grande autonomia religiosa e administrativa às lideranças e comunidades locais. Vejamos alguns exemplos desse fenômeno. 
A denominação evangélica de maior sucesso numérico no Brasil nas últimas duas décadas, a Universal, não só adota governo eclesiástico episcopal como é comandada com mão de ferro por Edir Macedo. Um de seus bispos e fundadores, deputado federal Carlos Rodrigues (PL/RJ), admite tranqüilamente que o governo eclesiástico da Universal "é uma ditadura". O que não o constrange nenhum pouco. Pois, para ele, "democracia dentro da igreja não funciona" "Eu não vejo", defende, "a igreja dessa forma democrática. Você não pode fazer uma assembléia pra perguntar, pra saber se o pastor deve comprar um órgão ou abrir um programa de televisão ou de rádio. Todas as igrejas democráticas não crescem... porque uma ovelha não pode mandar no pastor" (entrevista concedida a Fonseca, 2002, p. 222-223).

Embora líderes da Assembléia de Deus definam seu governo eclesiástico como congregacional ${ }^{6}$, na prática os pastores presidentes de ministérios concentram enorme poder clerical e centralizam a administração e os recursos das congregações sob sua jurisdição. O Ministério do Belém, em São Paulo, presidido pelo pastor José Wellington Bezerra da Costa, por exemplo, comanda mais de mil congregações na capital paulista. Diante de tantos casos desse tipo, Jean-Pierre Bastian (1994, p. 126) conclui que "a maior parte das denominações pentecostais tem dirigentes que são chefes, proprietários, caciques e caudilhos de um movimento religioso criado por eles mesmos e transmitido de pai para filho de acordo com o modelo patrimonial e/ou por nepotismo de reprodução". De modo geral, Bastian não foge à realidade. Haja vista que a adoção desse modelo patrimonial ou por nepotismo de transmissão de poder, cargos, empregos, templos e até da própria igreja grassa de modo inconteste entre boa parte das igrejas pentecostais.

Observações dessa natureza contradizem a perspectiva de que o pentecostalismo, em oposição ao sacerdotalismo católico, democratiza o acesso ao sagrado e à hierarquia eclesiástica. Não cabe discutir, aqui, a questão do acesso de católicos e pentecostais ao sagrado. Interessa avaliar a suposta democratização pentecostal do acesso à hierarquia eclesiástica. Para defen-

\footnotetext{
${ }^{6}$ Em seu quinto mandato consecutivo na presidência da Convenção Geral das Assembléias de Deus no Brasil (CGADB), pastor José Wellington Bezerra da Costa afirma: "Nosso sistema ainda é o congregacional". Em seguida, contudo, ao explicar como funciona esse sistema, assevera que as congregações estão vinculadas à igreja-sede, que, entre suas funções, centraliza a administração das congregações, o que, segundo ele, "significa que toda a renda vem para cá", isto é, para a sede (Eclésia, 51, fev. 2000). Com efeito, quem manda ou detém o poder supremo é o pastor que preside o ministério. Seus comandados, os pastores e presbíteros das igrejas e congregações locais, possuem pouca autonomia. Além disso, cabe observar que o advérbio "ainda", aparentemente deslocado e desnecessário na frase do pastor Wellington, talvez revele mais que um simples lapso. E se a Convenção Geral ainda é liderada por um pastor, a Convenção Nacional das Assembléias de Deus (Conamad) tem como presidente vitalício Manoel Ferreira, ex-pastor que, em meados de 2001, se autoproclamou bispo, embora não tenha substituído formalmente o velho governo eclesiástico congregacional pelo episcopal.
} 
der esse ponto de vista, Willems (1967) e Lalive D'Epinay (1970), por exemplo, tomam como evidência o fato de que crentes pobres e pouco instruídos, mesmo sem formação teológica, podem ascender aos postos de presbítero, pastor e bispo. Há que se ponderar, porém, que, na maioria das igrejas pentecostais, como frisa Rolim (1985, p. 124), as mulheres são excluídas do corpo sacerdotal e os leigos não participam da escolha de seus dirigentes pastorais nem das instâncias de poder que selecionam os membros do clero e definem os critérios que regulam o acesso aos cargos eclesiásticos. Tendo em vista que tais observações correspondem aos fatos, não há como sustentar a idéia de que o acesso à hierarquia das denominações pentecostais é democrático. O fato desse acesso dispensar, embora cada vez menos, os candidatos ao pastorado da posse de diplomas em seminários e faculdades teológicos significa tão-somente que o crente pouco escolarizado e com reduzido saber teológico enfrenta diminutas exigências desse tipo para ascender à (e na) hierarquia eclesiástica. Fato que só comprova que o acesso à hierarquia dessas igrejas não é elitizado.

Ladeando a verticalização clerical e a centralização administrativa e financeira, estão as opções entusiásticas pelo marketing e pela organização e gestão em moldes empresariais. Opções eficientes para quem deseja dirigir a igreja como uma empresa de fato. $\mathrm{O}$ que parece ser o caso do apóstolo Estevam Hernandes Filho. Ex-gerente de marketing da Xerox do Brasil e da Itautec, ele não só emprega sua pregressa experiência profissional para ampliar seu empreendimento religioso como, nas suas próprias palavras, trata a igreja que preside como uma "empresa no mercado". Líder da Renascer em Cristo - administrada pela Fundação Renascer, a mesma que no início de 1999 arrendou a Rede Manchete -, Hernandes é autor da apostila intitulada "A igreja usando o marketing como arma espiritual", baseada nas teorias de Phillip Kotler, norte-americano tido como o maior especialista mundial nas técnicas de marketing. Na apostila, afirma que o cristão deve pregar o Evangelho com "intrepidez", ocupar "as principais posições" na sociedade e efetuar um "evangelismo criativo", por meio do uso de "teatro, shows, rádio, TV, outdoor, cartazes, revistas, panfletos, cartões, camisetas, jornal, marketing direto". Propõe a segmentação - entre executivos, jovens, crianças, adolescentes e pessoas carentes - e contextualização da mensagem, destacando que ela deve ser transmitida de "forma sutil e adequada ao público-alvo". No plano organizacional e administrativo, o apóstolo admite de vez seu projeto empresarial, acentuando que a igreja deve ser "encarada como uma empresa no mercado". Para efetuar tal tarefa, deve contar com profissionais e voluntários nos departamentos administrativo, financeiro, de marketing, de imprensa e comunicações; profissionais encarregados de "elaborar planejamentos de crescimento". Além de advogar a legitimidade da igreja "como fator gerador de auto-sustento" de pastores, evangelistas e 
membros, Hernandes defende que "não é vergonha obter lucro" para sustento próprio e para a "expansão do reino". Conclusão lógica para quem apregoa que a igreja deve ser encarada como uma empresa no mercado, caso em que não há razão para sentir-se indigno ou inescrupuloso por granjear lucro na direção e gestão desse empreendimento. A Teologia da Prosperidade, decerto, cumpre importante papel no reforço da convicção pastoral de que a obtenção de lucro no desempenho das atividades denominacionais, sejam elas administrativas ou religiosas, não constitui problema ético ou religioso.

Merece destaque o fato de que a emergência da adoção de modelos organizacionais e de gestão de cunho empresarial não data de agora. Já nos anos 70 Duglas Monteiro (1979), ao analisar duas concentrações pentecostais de cura divina, interpreta os grupos promotores desses eventos como agências dotadas de corpo burocrático e de estrutura semi-empresarial, tendentes a "organizar-se enquanto empresas destinadas à produção e distribuição de bens e de serviços religiosos". Para o pesquisador, essa tendência decorreria do "desenvolvimento das sociedades industriais capitalistas". Partindo das formulações de Monteiro, de que o sacral e o mágico estariam sendo "administrados segundo normas empresariais da organização capitalista" pelo chamado pentecostalismo de cura divina, Rubem Alves (1978, p. 136-138) interpreta o fenômeno como redução do popular (ou dessa religião popular) "à condição de mercadoria", vendida e comprada "segundo a lógica dos valores de troca". O que confere às "empresas de cura divina" sua configuração específica, segundo Alves, é a comercialização de bens espirituais. A seu ver, portanto, os grupos de cura divina não constituem uma manifestação religiosa que lança mão de métodos empresariais, mas sim empresas cuja singularidade reside na produção e comercialização de bens espirituais (Alves, 1979, p. 115).

A despeito das críticas de Alves a esse grupo religioso, tal como Monteiro, ele aponta a emergência de algo até então absolutamente inédito no campo religioso brasileiro: o início da transformação de pequenas seitas pentecostais, mal organizadas e desprovidas de corpo burocrático, em empresas produtoras de bens de salvação, administradas segundo a lógica do mercado. Fenômeno que Monteiro associa à difusa influência da expansão capitalista sobre o próprio funcionamento e organização dessas instituições religiosas.

Além da influência da economia de mercado stricto sensu nas organizações religiosas, cabe observar que a própria situação pluralista e de mercado, como frisa Berger (1985, p. 150), tende a levar à racionalização e burocratização das estruturas sociorreligiosas, o que inclui a profissionalização de seus quadros eclesiásticos e administrativos. Se, no interior de uma eco- 
nomia de mercado, os grupos religiosos não têm como se livrar dos efeitos da crescente racionalização burocrática e administrativa da sociedade abrangente, num contexto religioso pluralista, eles se vêem às voltas com as pressões exercidas pelo mercado religioso.

Nos anos 70 Monteiro e Alves já vinham observando a metamorfose de pequenas seitas em empresas de bens de salvação. A maioria dos pesquisadores, porém, teve sua atenção despertada para esse fenômeno somente na década de 90. Eles, contudo, não foram os únicos. Nesse período, o sucesso empresarial e midiático da Igreja Universal chamara a atenção de toda a sociedade brasileira. Com a intensa mobilização da grande imprensa para cobrir a surpreendente compra da Rede Record pela Universal em 1990, logo seus líderes, suas crenças e práticas religiosas e suas aquisições milionárias se tornaram tema de conversas, comentários, críticas e piadas no diaa-dia. Pois, como podia uma desconhecida seita pentecostal, nascida no subúrbio carioca apenas 13 anos antes, cujo primeiro templo funcionara no salão de uma acanhada ex-funerária, repentinamente desembolsar $45 \mathrm{mi}$ lhões de dólares na compra de uma tradicional emissora paulista de TV? Nesse contexto era praticamente impossível dissociar esta igreja e a vertente que ela encabeça, a neopentecostal, das atividades empresariais e das estratégias midiáticas e de marketing. Vários pesquisadores, então, perceberam e teceram tal associação entre o êxito da Universal - mas não só dela - no campo religioso, político, midiático e sua gestão empresarial. Seguem abaixo, de modo sucinto, algumas de suas observações a esse respeito.

Ari Pedro Oro (1992) afirma que a liderança neopentecostal segue, na gestão da organização eclesiástica, um "modelo empresarial", que se baseia na divisão social do trabalho religioso e administrativo, no uso da mídia, na prestação de serviços religiosos mediante pagamento e na adoção de mecanismos diversos para arrecadar recursos. Antônio Gouvêa Mendonça (1992, p. 51) frisa que a vertente neopentecostal apresenta "características empresariais de prestação de serviços ou de oferta de bens de religião mediante recompensa pecuniária" e possui "modernos sistemas de administração e de marketing". Yara Monteiro (1995, p. 7, 17), contrapondo Igreja Universal à Congregação Cristã no Brasil, que não cobra dízimos nem remunera seus anciãos, assevera que o neopentecostalismo "caracteriza-se, em especial, pela 'comercialização' de bens simbólicos". Alexandre Brasil Fonseca (1997, p. 177) observa que a constituição de "igrejas-empresas, holdings da fé, é uma necessidade determinada pela presença na mídia". Nesse sentido, vale repisar que a Teologia da Prosperidade, disseminada no meio evangélico brasileiro por igrejas neopentecostais, surge intimamente associada ao televangelismo. Pressionados pelas despesas crescentes de seus projetos, que, tanto nos Estados Unidos como no Brasil, foram se tornando cada vez 
mais ambiciosos, os televangelistas refinaram as formas de levantar fundos, integrando os apelos financeiros à teologia (Hadden, 1993; Mariano, 1999, p. 152). Para Leonildo Silveira Campos (1996, p. 186-214), a Universal consiste numa "organização religiosa-empresarial" que faz da "marketização do sagrado" sua principal estratégia para granjear sucesso no mercado religioso. Segundo Flávio Pierucci (Pierucci e Prandi, 1996, p. 281-282), "a Igreja Universal inova muito em matéria de comportamento religioso, especialmente quando concebe abertamente a igreja como empresa econômica e a religião como fonte de lucro e enriquecimento pessoal". Daí o autor nomeá-la e a suas congêneres de "igrejas-empresas", especializadas na oferta de "respostas efetivas à demanda efetiva dos adeptos ou clientes por resultados efetivos" (Pierucci, 1997, p. 252). Reginaldo Prandi (Pierucci e Prandi, 1996, p. 258) afirma que os pastores da Universal "são empreendedores com baixa ou nula formação teológica, mas que devem demonstrar grande capacidade de atrair público e gerar dividendos para a igreja, de acordo com um know-how administrado empresarialmente pelos bispos, a igreja já estruturada como negócio".

Como se pôde observar, os pesquisadores referem-se à Universal como empresa e holding, cujas atividades empresariais ${ }^{7}$, mercantilistas e de marketing, além de objetivarem a defesa de seus interesses organizacionais e religiosos, visam ao lucro e, para alguns, resultam em exploração financeira e, na esteira disso, proporcionam enriquecimento ilícito dos responsáveis pela gestão e comercialização dos serviços e produtos mágico-religiosos. O ex-ministro da Fazenda Roberto Campos sintetiza a percepção de muitos sobre esse fenômeno, pontificando que "a praga do protestantismo é sua mercantilização" .

Observa-se que o pluralismo religioso, a concorrência inter-religiosa e o tino empresarial da Universal aparecem umbilicalmente associados em algumas das citações acima. Até porque não há como dissociar, histórica e analiticamente, o surgimento de "igrejas-empresas" da crescente pluralização e concorrência religiosas no Brasil, que resultaram na consolidação de um vigoroso mercado religioso. Daí que, atualmente, toda vez que se concebe qualquer projeto expansionista nos meios pentecostais, de imediato, surgem como paradigmas - embora muitas vezes criticados e sumariamente

\footnotetext{
${ }^{7}$ A constatação acerca do caráter empresarial e dos métodos heterodoxos de arrecadação da Universal gerou a discussão acadêmica sobre a defesa do consumidor religioso por meio dos poderes públicos e sobre o papel do Estado - não obstante os limites políticos e jurídicos para sua ação no campo religioso - na regulação de organizações religiosas que, embora se beneficiem de total isenção fiscal, desenvolvem atividades com fins lucrativos (Pierucci, in Pierucci e Prandi, 1996, p. 275-285).

${ }^{8}$ Cf. "Deus, fé e política", de Roberto Campos, Veja 25 anos. Reflexões para o futuro. São Paulo: Abril, 1993, p. 226.
} 
rejeitados nesse meio - o modelo religioso e organizacional da Universal e procedimentos e estratégias gerenciais semelhantes aos que orientam a conduta dos agentes do mercado stricto sensu.

No caso específico da Igreja Universal, pode-se afirmar, resumidamente, que sua organização empresarial, liderada por um governo episcopal centralizado em seu fundador e bispo primaz, se baseia na concentração da gestão administrativa, financeira e patrimonial, na formação de quadros eclesiástico e administrativo profissionalizados ${ }^{9}$, na adoção de estratégias de marketing, na fixação de metas de produtividade para os pastores locais, num eficiente e agressivo mecanismo de arrecadação de recursos, num pesado investimento em evangelismo eletrônico, empresas de comunicação e noutros negócios que orbitam em torno de atividades da denominação, na abertura de grandes templos e na provisão diária, metódica e sistemática de elevada quantidade de serviços mágico-religiosos.

Em razão de o desempenho dos governos eclesiásticos verticalizados depender acentuadamente da competência religiosa e gerencial de seus dirigentes, o perfil do líder pentecostal bem-sucedido cada vez mais se assemelha ao de um empresário ou administrador de empresas. De modo que, atualmente, se espera que o líder denominacional saiba lidar com as especificidades do mercado religioso, adequando seu produto (mensagens, práticas e ritos religiosos) aos interesses materiais e ideais dos consumidores, publicizando-o entre seu público-alvo, a fim de atrair e recrutar o maior número possível de adeptos e formar e cativar novas clientelas. Isto implica, de um lado, conhecer os interesses de seu público-alvo, de outro, atendê-los do modo mais eficaz possível e por todos os meios disponíveis. Nas últimas décadas, a efetivação de tal habilidade religiosa, empresarial e "mercadológica" resultou na opção denominacional pela fórmula que consiste em unir o que há de mais moderno e eficiente nas áreas de propaganda, comunicação e marketing - uso evangelístico de rádio, TV, música, internet, jornais, literatura - com o que há de mais tradicional no plano religioso: promessas de milagres, práticas mágicas, curas sobrenaturais, rituais de exorcismo ou libertação de espíritos demoníacos.

Para ser viabilizado, o evangelismo eletrônico depende da posse e do

\footnotetext{
${ }^{9}$ Diferentemente do que se passa, por exemplo, nas igrejas Congregação Cristã, Assembléia de Deus, Evangelho Quadrangular e Deus é Amor, a profissionalização do clero permite que a maioria dos pastores - formados em larga escala e a toque de caixa - da Universal trabalhe em período integral e em regime de dedicação exclusiva, o que constitui extraordinária vantagem competitiva. Por isso, enquanto suas principais concorrentes no campo pentecostal realizam cerca de meia dúzia de cultos públicos por semana, os templos da Universal funcionam como uma verdadeira "linha de montagem", sendo abertos diariamente para a celebração de cinco a seis cultos diários.
} 
dispêndio de recursos financeiros, que podem atingir somas elevadíssimas dependendo do porte dos empreendimentos midiáticos. Daí a relevância e funcionalidade da Teologia da Prosperidade ${ }^{10}$ para dilatar a arrecadação das igrejas que mais investem no evangelismo em rádio e TV. Não é à toa que Edir Macedo - que é a um só tempo um dos maiores expoentes do televangelismo e dessa teologia no Brasil - considera que "o dinheiro é uma ferramenta sagrada usada na obra de Deus" e, numa inusitada analogia biológica, o "sangue da Igreja" (Macedo, 2000, p. 52; 1986, p. 97). Essa perspectiva teológica, não por acaso, tem sido associada ao emprego de métodos heterodoxos de arrecadação e, com isso, gerado um sem-número de acusações de exploração financeira dos incautos.

A opção por seguir a férrea lógica de mercado para defender seus interesses institucionais e superar a concorrência, com efeito, incidiu tanto no cerne da missão religiosa quanto na organização e administração de diversas igrejas pentecostais. Em razão disso, suas lideranças eclesiásticas passaram, estrategicamente, a abandonar crenças e práticas contraculturais - isto é, sectárias e ascéticas - e a adotar métodos de ação e de organização típicos da racionalidade empresarial. Daí a crescente elevação dos investimentos na mídia eletrônica, a disseminação do uso de técnicas de marketing, a ênfase na maximização da arrecadação financeira e na sistematização da oferta de serviços mágicos, a diminuição das exigências comportamentais e a notória adaptação da mensagem e da liturgia às preferências e aos interesses materiais e ideais dos estratos pobres e, em menor grau, também de segmentos da classe média.

Para ampliar sua eficiência evangelística, porém, elas não se limitam a investir na mídia e a pregar com afinco a mensagem redentora. Procuram também "falar a língua" desse público-alvo. Pragmáticas e imbuídas do desígnio conversionista - já que levam a sério a missão ordenada pelo Deus cristão de "ir e fazer discípulos de todas as nações" (Mateus 28: 19) -, as igrejas pentecostais mais bem-sucedidas na competição religiosa, além de maximizarem a provisão de compensações concretas e imediatas neste mundo, procuram adaptar sua mensagem religiosa (conteúdo, forma e meios de transmissão) à vida material e cultural dos estratos pobres, a fim de provê-los de sentido, significação do porquê se encontram vivendo como vivem e justificação de sua existência numa dada posição social, fornecendolhes recursos simbólicos e rituais para mudar subjetivamente de vida e vivas esperanças de habitar o paraíso celestial. Resulta disso a "opção preferencial" deles por igrejas que, como estas, procuram mobilizar todos os esforços evangelísticos para atraí-los, persuadi-los e recrutá-los por meio do uso da

\footnotetext{
${ }^{10}$ Sobre a Teologia da Prosperidade, ver Mariano (1996).
} 
mídia, da ênfase na oferta de serviços mágicos, da evangelização pessoal, da propaganda dos testemunhos de conversão e de bênçãos materiais, da desenfreada abertura de novos templos e congregações, do alto teor emocional dos cultos, da música gospel e, no caso da Universal, do trabalho pastoral em tempo integral.

São diversos os efeitos da liberdade, do pluralismo e do mercado religiosos, derivados da separação Igreja-Estado, no campo religioso brasileiro. Certas mudanças apontadas no pentecostalismo, em particular nas igrejas pentecostais citadas, exemplificam emblematicamente tais efeitos. Mostram também que esse grupo religioso adaptou-se com extrema eficiência à situação pluralista e de mercado, o que vem se constituindo numa de suas principais vantagens competitivas sobre a concorrência. Concorrência que, por sua vez, vem cedendo cada vez mais às pressões e à lógica do mercado.

\section{Referências}

ALVES, Rubem A. A volta do sagrado: os caminhos da sociologia da religião no Brasil. Religião e Sociedade, 3, out. 1978, p. 109-141.

A empresa da cura divina: um fenômeno religioso? In: VALLE, Edênio (Org.), A cultura do povo. São Paulo: Cortez e Moraes, Educ, 1979.

BASTIAN, Jean-Pierre. La mutación del protestantismo latinoamericano: una perspectiva socio-histórica. In: GUTIERREZ, Tomás (Org.), Protestantismo y cultura en América Latina: aportes y proyecciones. Quito, Equador: Clai-Cehila, 1994.

BERGER, Peter L. A market model for the analisys of ecumenicity. Social Research, v. 30, 1963, p. 77-93.

. O Dossel Sagrado: Elementos para uma sociologia da religião. São Paulo: Paulinas, 1985.

CAMPOS, Leonildo Silveira. Teatro, templo e mercado: uma análise da organização, rituais, marketing e eficácia comunicativa de um empreendimento neopentecostal - Igreja Universal do Reino de Deus. São Bernardo do Campo: Doutorado em Ciências da Religião, IMES, 1996.

CHAVES, Mark. On the rational choice approach to religion. Journal for the Scientific Study of Religion. v. 34, $\mathrm{n}^{\circ} 1,1995$, p. 98-104.

COLLINS, Randall. Book review of $A$ theory of religion, de STARK, Rodney; BAINBRIDGE, Williams Sims. Journal for the Scientific Study or Religion, v. 32, nº 4, 1993, p. 402-406.

Stark and Bainbridge, Durkheim and Weber: theoretical comparisons. In: YOUNG, Lawrence A. (Org.), Rational choice theory and religion: summary and assessment. New York: Routledge, 1997, p. 161-180.

D'EPINAY, Christian Lalive. O refúgio das massas. Rio de Janeiro: Paz e Terra, 1970.

ELLISON, Christopher G. Rational choice explanations of individual religious behavior: notes on the problem of social embeddedness. Journal for the Scientific Study of Religion. v. 34, $\mathrm{n}^{\circ} 1,1995$, p. 89-97.

FINKE, Roger. The consequences of religious competition: supply-side explanations for religious change. In: Young, Lawrence A. (Org.), Rational choice theory and religion: summary and assessment. New York, Routledge, 1997, p. 45-64.

FINKE, Roger; STARK, Rodney. The churching of America - 1776-1990: Winners and losers in our religious economy. New Brunswick, New Jersey: Rutgers University Press: 1992. 
FONSECA, Alexandre Brasil. Evangélicos e mídia no Brasil. Rio de Janeiro: Dissertação de Mestrado em Sociologia, IFCS-UFRJ, 1997.

Secularização, pluralismo religioso e democracia no Brasil. Um estudo sobre evangélicos na política nos anos 90. Tese de doutorado em sociologia, São Paulo: FFLCH-USP, 2002.

FORNI, Floreal. Teoría económica de la religión: el pluralismo religioso em Buenos Aires. Paper apresentado na X Jornadas sobre Alternativas Religiosas na América Latina, Buenos Aires, 2000, 13 pág.

FRESTON, Paul. Protestantes e política no Brasil: da Constituinte ao impeachment. Campinas, Tese de Doutorado em sociologia, IFCH-Unicamp, 1993.

FRIGERIO, Alejandro. El futuro de las religiones mágicas em Latinoamérica. Paper apresentado nas VIII Jornadas sobre Alternativas Religiosas na América Latina, São Paulo, 1998, 33 pág.

Desregulación del mercado religioso y expansión de nuevas religiones: uma interpretación desde la oferta. Paper apresentado no XXII Encontro anual da ANPOCS, Caxambu, Minas Gerais, 1998b, 20 p.

GIUMBELLI, Emerson Alessandro. O fim da religião: controvérsias acerca das "seitas" e da "liberdade religiosa" no Brasil e na França. Rio de Janeiro: Tese de doutorado em antropologia social, Rio de Janeiro: Museu Nacional, UFRJ, 2000.

HADAWAY, C. Kirk, MARLER, Penny Long, CHAVES, Mark. Overreporting church attendance in America: evidence that demands the same verdict. American Sociological Review, v. 63, n. 1, feb. 1998, p. 122-130.

HADDEN, Jeffrey K. The rise and fall of American televangelism. The Annals of the American Academy of Political and Social Science, v. 527, 1993, p. 113-130.

HORTAL, Jesús Sánchez. Religião, liberdade e controle. Veredas. Belo Horizonte, v. 1, n. ${ }^{\circ}$, 2000, p. 87-93.

IANNACCONE, Laurence R. Why strict churches are strong. American Journal of Sociology, v. 99,1994 , p. $1180-1211$.

Voodoo economics? Reviewing the rational choice approach to religion. Journal for the scientific study of religion, v. 34, nº 1, 1995, p. 76-89.

Rational choice: framework for the scientific study of religion. In: YOUNG, Lawrence A. (Org.), Rational choice theory and religion: summary and assessment. New York: Routledge, 1997, p. 25-44.

MACEDO, Edir. Nos passos de Jesus. Rio de Janeiro: Universal, 1986.

Vida com abundância. 14. ed. Rio de Janeiro: Universal Produções, 2000.

MARIANO, Ricardo. Os neopentecostais e a Teologia da Prosperidade. Novos Estudos Cebrap, n. 44, mar. 1996, p. 24-44.

Neopentecostais: sociologia do novo pentecostalismo no Brasil. São Paulo: Edições Loyola, 1999.

. Análise sociológica do crescimento pentecostal no Brasil. Tese de doutorado em sociologia, São Paulo: FFLCH-USP, 2001.

MARIANO, Ricardo, PIERUCCI, Antônio Flávio. O envolvimento dos pentecostais na eleição de Collor. Novos Estudos Cebrap, n. 34, 1992, p. 92-106.

MENDONÇA, Antonio Gouvêa. Sindicato de mágicos: pentecostalismo e cura divina (desafio histórico para as igrejas). Estudos de Religião, São Bernardo do Campo, n. 8, out. 1992, p. 49-59.

MONTEIRO, Duglas Teixeira. Igrejas, seitas e agências: aspectos de um ecumenismo Popular. In: VALLE, Edênio. (Org.), A cultura do povo. São Paulo: Cortez e Moraes, Educ, 1979, p. 81-111. 
MONTEIRO, Yara Nogueira. Pentecostalismo no Brasil: os desafios da pesquisa. In: Revista de Cultura Teológica, São Paulo: Faculdade de Teologia Nossa Senhora da Assunção, v. 13, out-dez. 1995, p. 7-20.

ORO, Ari Pedro. 'Podem passar a sacolinha': um estudo sobre as representações do dinheiro no neopentecostalismo brasileiro. Cadernos de Antropologia, v. 9, 1992, p. 7-44. Programa de Pós-graduação em Antropologia Social da UFRGS.

PIERUCCI, Antônio Flávio. Representantes de Deus em Brasília: a bancada evangélica na Constituinte. Ciências Sociais Hoje, 1989. São Paulo: Vértice / Revista dos Tribunais, ANPOCS, 1989, p. 104-132.

Secularização em Max Weber. Da contemporânea serventia de voltarmos a acessar aquele velho sentido. Revista Brasileira de Ciências Sociais, v. 13, n. 37, jun. 1998, p. 4373.

PIERUCCI, Antônio Flávio. Fim da união Estado-Igreja ampliou oferta de religiões. Folha de S. Paulo, Caderno especial Busca pela Fé, 26/12/1999.

Liberdade de cultos na sociedade de serviços. In: PIERUCCI, Antônio Flavio \& PRANDI, Reginaldo. A realidade social das religiões no Brasil: religião, sociedade e política. São Paulo: Hucitec, 1996, p. 275-285.

PRANDI, Reginaldo. Cidade em transe: religiões populares no Brasil no fim do século da razão. Revista USP, v. 11, 1991, p. 65-70.

Religião paga, conversão e serviço. In: PIERUCCI, Antônio Flavio; PRANDI, Reginaldo. A realidade social das religiões no Brasil: religião, sociedade e política. São Paulo: Hucitec, 1996, p. 257-273.

ROLIM, Francisco Cartaxo. Pentecostais no Brasil: uma interpretação sócio-religiosa. Rio de Janeiro: Vozes, 1985.

SHEA, Chris. Supply and demand among the faithful. New York Times, 24/3/2001.

SHERKAT, Darren E. "Embedding religious choices: preferences and social constraints into rational choice theories of religious behavior". In: YOUNG, Lawrence A. (Org.), Rational choice theory and religion: summary and assessment. New York: Routledge, 1997, p. 65-85.

STARK, Rodney, BAINBRIDGE, William Sims. The future of religion: Secularization, revival, and cult formation. Berkeley: University of California Press, 1985.

A theory of religion. New Brunswick: Rutgers University Press, 1996.

STARK, Rodney, IANNACCONE, Laurence. Sociology of religion. In: BORGATTA, Edgar F., BORGATTA, Marie L. (Eds.), Encyclopedia of Sociology. New York: MacMillan Publishing Company, v. 4, 1992, p. 2029-2037.

Rational choice propositions about religious movements. Religion and social order, v. 3A, 1993, p. 241-261.

WARNER, Stephen. Work in progress toward a new paradigm for the sociological study of religion in the United States. American Journal of Sociology, v. 98, 1993a, p. 1044-1093.

Book review of The churching of America, 1776-1990: winners and losers in our religious economy, de FINKE, Roger, STARK, Rodney. Journal for the Scientific Study of Religion. v. 32, no 3, 1993b. p. 295-297.

WILLEMS, Emilio. Followers of the new faith culture change and rise of protestantism in Brasil and Chile. Nashville: Vanderbilt University Press, 1967. 